\title{
El derecho al aborto en América Latina y el Caribe
}

The right to abortion in Latin America and the Caribbean

Norma Graciela Chiapparrone

Recibido: 31/01/2018

Aceptado: 03/09/2018

\section{RESUMEN}

En Latinoamérica y El Caribe al menos treinta países consideran el aborto un delito; así las mujeres que desean interrumpir un embarazo no sólo ponen en riesgo su salud, sino propia libertad. Estas situaciones las impactan diferencialmente dependiendo de la raza, etnia, religión, educación, nivel de ingresos, entre otras razones. La violación del secreto médico, el incumplimiento al deber de confidencialidad y la recurrencia a la objeción de conciencia por parte de los médicos/as, también son variables que operan negativamente. La alianza del patriarcado con el capitalismo, como sistema de dominación y subordinación de las mujeres, es el escenario para la violación de los derechos sexuales y reproductivos de mujeres y niñas. El disciplinamiento que pretende imponerse, impide alcanzar la libertad y autonomía de nuestros cuerpos.

Palabras clave: aborto; derechos sexuales y reproductivos; maternidad normativizada; patriarcado; feminismo

\begin{abstract}
In Latin America and the Caribbean at least thirty countries consider abortion a crime; thus, women who want to interrupt a pregnancy not only risk their health, but also their own freedom. These situations have a different impact on them depending on race, ethnicity, religion, education, income level, among other reasons. The violation of medical secrecy, the breach of duty of confidentiality and the recurrence of conscientious objection by doctors, are also variables that operate negatively. The alliance of patriarchy with capitalism, as a system of domination and subordination of women, is the scenario for the violation of the sexual and reproductive rights of women and girls. The imposing discipline prevents women from achieving the freedom and autonomy of their bodies.
\end{abstract}

Keywords: abortion; sexual and reproductive rights; normative motherhood; patriarchy; feminism

Norma Graciela Chiapparrone es procuradora y licenciada en Derecho por la Universidad Nacional de Buenos Aires. Máster en Igualdad, Equidad en el Desarrollo, de Cooperación de Vic (España). Correo electrónico: normach@live.com.ar

Cómo citar este artículo: Chiapparrone, N. G. (2018). El derecho al aborto en América Latina y el Caribe. Atlánticas. Revista Internacional de Estudios Feministas, 3 (1), 192-223 doi: http://dx.doi.org/10.17979/arief.2018.3.1.3300 


\section{PLANTEO DEL TEMA}

En América Latina y el Caribe coexisten leyes que van desde la despenalización hasta la prohibición absoluta del aborto, siendo el porcentaje más alto el que corresponde al sistema de despenalización parcial y por causales. Todo ese entramado legal no protege a las mujeres que deciden abortar, pues los obstáculos y dificultades que deben enfrentar son muchos, por tanto ante la ineficacia de las respuestas de los sistemas de salud en cada uno de sus países, acuden a instancias internacionales en demanda por la violación de sus derechos humanos, entendiendo que los derechos sexuales y reproductivos se consideran tales. De ahí que contamos con pronunciamientos y recomendaciones de organismos regionales e internacionales y de los comités de los tratados que en distintos momentos y situaciones han reconvenido a los Estados para que despenalicen el aborto en algunos supuestos.

La cuestión es: ¿A quiénes protegen las leyes restrictivas en materia de aborto? ¿Cuáles son sus fundamentos? ¿De qué hablamos cuando hablamos de aborto?, Ineludiblemente no es sólo una cuestión de lege data, ni de los derechos que emergen del derecho internacional de los derechos humanos, tan prolífico en la materia. El feminismo como teoría crítica y política, como movimiento emancipador que lleva más de trescientos años desvelando el latrocinio del patriarcado sobre la mitad de la humanidad, ha puesto en el centro de la escena este tema a partir del feminismo radical de los setenta. A pesar de ello y de los avances legislativos, actualmente los embates contra los derechos de las mujeres -en particular el derecho a decidir sobre sus cuerpos- van de la mano del avance liberal y conservador que está cooptando los gobiernos en distintos países del mundo.

En este trabajo abordaré sucintamente la situación jurídica del aborto en el mundo como punto de partida, y luego, específicamente para la región de América Latina y El Caribe, ubicando el tratamiento normativo en algunos de los sistemas conocidos, desde la prohibición absoluta, hasta la permisión en sus distintas modalidades.

La hipótesis central que recorre este trabajo desde mi posición como feminista es que las mujeres son sometidas y disciplinadas por el patriarcado, como sistema de dominación y subordinación hacia los hombres, usando sus cuerpos, 
normativizando la maternidad, sancionando todo intento de emancipación que vinculen el deseo y la razón en el ejercicio y goce de los derechos sexuales y reproductivos.

La metodología seguida partiendo del aborto como un derecho de las mujeres, se basa en un enfoque de derechos humanos, un repaso de las legislaciones vigentes en la región, y también aporto decisiones de organismos internacionales que condenan a los Estados partes por violaciones a los derechos humanos de las mujeres, considerando tales los derechos sexuales y reproductivos.

\section{DERECHOS SEXUALES Y REPRODUCTIVOS}

\subsection{El feminismo radical y su proyección al presente}

La Asamblea General de las Naciones Unidas aprobó la Convención el 18 de diciembre de 1979, que entró en vigor como tratado internacional el 3 de septiembre de 1981 tras su ratificación por 20 países. Conocida por sus siglas en inglés, la CEDAW ha sido ratificada por los Estados de América Latina y el Caribe, y ha sido y es un instrumento fundamental para la garantía de los derechos humanos de las mujeres, en nuestra región y a nivel mundial. La labor del Comité CEDAW en tanto órgano de monitoreo de la convención no sólo es importante por las Recomendaciones emitidas en los casos sometidos a su conocimiento, sino por el dictado de las Observaciones Generales que interpretan el texto de dicho instrumento.

Su objetivo fundamental es eliminar la discriminación y lograr la igualdad de género; sin embargo, sigue siendo un desafío que esa igualdad por ahora sustantiva, sea efectivamente real. He incluido a modo de muestra algunos casos en que se ha aplicado la Cedaw y que permiten proyectar la dimensión de lo que está plasmado en su texto, sus recomendaciones y en las observaciones generales.

\subsection{La Convención para la eliminación de todas las formas de discriminación contra la mujer}

La Asamblea General de las Naciones Unidas aprobó la Convención el 18 de diciembre de 1979, que entró en vigor como tratado internacional el 3 de 
septiembre de 1981 tras su ratificación por 20 países. Conocida por sus siglas en inglés, la CEDAW ha sido ratificada por los Estados de América Latina y el Caribe, y ha sido y es un instrumento fundamental para la garantía de los derechos humanos de las mujeres, en nuestra región y a nivel mundial. La labor del Comité CEDAW en tanto órgano de monitoreo de la convención no sólo es importante por las Recomendaciones emitidas en los casos sometidos a su conocimiento, sino por el dictado de las Observaciones Generales que interpretan el texto de dicho instrumento.

Su objetivo fundamental es eliminar la discriminación y lograr la igualdad de género; sin embargo, sigue siendo un desafío que esa igualdad por ahora sustantiva, sea efectivamente real. He incluido a modo de muestra algunos casos en que se ha aplicado la CEDAW y que permiten proyectar la dimensión de lo que está plasmado en su texto, sus recomendaciones y en las observaciones generales.

\subsection{La importancia y el impacto de Beijing y El Cairo}

Después de la aparición del feminismo radical debimos esperar un par de décadas para que el término derechos reproductivos como tal, fuese plasmado en el derecho internacional. Fue en 1994 en la Conferencia Mundial sobre la Población y el Desarrollo, celebrada en el Cairo, durante la cual se estableció que los DSR resultan claramente derechos humanos y deben entenderse en tanto tales desde una perspectiva de género (Facio, 2008, 25); y

“...se basan en el reconocimiento del derecho básico de todas las parejas y todas las personas a decidir libre y responsablemente el número de sus hijos, el espaciamiento de los nacimientos y el intervalo entre estos y a disponer de la información y de los medios para ello, y el derecho a disfrutar del más elevado posible nivel de salud sexual y de salud de la reproducción. También incluyen el derecho de todos a adoptar decisiones relativas a la reproducción sin sufrir discriminación, coacciones ni violencia, con arreglo a lo expresado en los documentos de derechos humanos. " (23)

Luego, la Cuarta Conferencia Mundial sobre la Mujer, celebrada en Beijing en 1995, por un lado, ratificará el planteamiento sostenido en el Cairo, pero deja atrás la concepción de la planificación familiar vinculada estrictamente con la 
familia. En Beijing se puso en el centro de la escena a la mujer en el marco de un planteamiento integral de los derechos humanos, estableciéndose que éstos juegan un rol esencial en relación con la salud sexual y reproductiva (Hunt, 2004: 5). De ello se sigue la importancia del párrafo 96 de Beijing, cuando establece que:

"Los derechos humanos de la mujer incluyen su derecho a tener control sobre las cuestiones relativas a su sexualidad, incluida su salud sexual y reproductiva, y decidir libremente respecto de esas cuestiones, sin verse sujeta a la coerción, la discriminación y la violencia. Las relaciones igualitarias entre la mujer y el hombre respecto de las relaciones sexuales y la reproducción, incluido el pleno respeto de la integridad de la persona, exigen el respeto y el consentimiento recíprocos y la voluntad de asumir conjuntamente la responsabilidad de las consecuencias del comportamiento sexual."

\section{4.- La Convención Interamericana para Prevenir, Sancionar y Erradicar la Violencia contra la Mujer. Accionar del Mesecvi}

En paralelo entre Beijing y El Cairo -temporalmente hablando - en nuestra región de LAC, se sancionó el 9/06/1994 la Convención Interamericana para Prevenir, Sancionar y Erradicar la Violencia contra la Mujer -conocida como Convención de Belém do Pará, ciudad donde se dictó-, la cual significó un saldo cualitativo de suma importancia. Excepción hecha de Cuba, todos los países de América Latina y el Caribe la han adoptado. Aborto y derechos sexuales y reproductivos no son términos que aparezcan expresamente en el texto de dicho instrumento, pero la existencia de esta Convención y la labor del grupo de expertas independientes que integran el MESECVI -Mecanismo de Seguimiento de la Convención de Belém do Pará- creado en 2004, y los informes que elaboran, fueron adquiriendo gran trascendencia en el tema en tratamiento. En tal sentido, el Primer Informe Hemisférico del MESECVI del año 2008, aunque no incluyó los derechos sexuales y reproductivos en el cuestionario de la Primera Ronda de Evaluación Multilateral, encontró que se evidenciaba una forma de violencia de género que nacía, precisamente, de la violación de importantes derechos humanos, entre los que incluyó el derecho a decidir sobre la vida reproductiva. Advirtieron las expertas que en aquellos países donde la legislación no protege ni reconoce los derechos sexuales y reproductivos se puede incurrir en graves violaciones a estos derechos, así como también dar 
lugar a altas tasas de morbilidad y mortalidad materna. Será entonces en el Segundo Informe del año 2012, que el MESECVI recomendó

“... despenalizar la interrupción del embarazo por motivos terapéuticos, sea para salvar la vida de la madre o sea para evitarle un daño grave o permanente a su salud física y mental, y despenalizar la interrupción del embarazo producido por violación." (2014:41).

\section{5.- Universo de los derechos reproductivos}

Alda Facio (2008, 25/26) considera que el universo de los derechos reproductivos se está ampliando constantemente, como consecuencia del dinamismo inherente a la teoría y práctica de los derechos humanos. La autora lista un conjunto de derechos humanos fundamentales, tomando en cuenta los ya reconocidos en instrumentos internacionales, regionales y nacionales. En estos derechos se incluyen:

\begin{tabular}{|c|c|}
\hline El derecho a la vida & $\begin{array}{l}\text { El derecho a no morir por causas } \\
\text { evitables relacionadas con el parto y } \\
\text { el embarazo. }\end{array}$ \\
\hline $\begin{array}{l}\text { El derecho a la libertad, seguridad, e } \\
\text { integridad personales }\end{array}$ & $\begin{array}{l}\bullet \text { El derecho a no ser sometida a } \\
\text { torturas ni a penas o tratos crueles, } \\
\text { inhumanos o degradantes. • El } \\
\text { derecho a estar libre de violencia } \\
\text { basada en el sexo y el género. • El } \\
\text { derecho a vivir libre de la explotación } \\
\text { sexual. }\end{array}$ \\
\hline $\begin{array}{l}\text { El derecho a decidir el número e } \\
\text { intervalo de hijos }\end{array}$ & $\begin{array}{l}\text { - El derecho a la autonomía } \\
\text { reproductiva. • El derecho a realizar } \\
\text { un plan de procreación con asistencia } \\
\text { médica o de una partera reconocida, } \\
\text { en un hospital o en un ambiente } \\
\text { alternativo. }\end{array}$ \\
\hline El derecho a la igualdad y a la no & El derecho a la no discriminación en \\
\hline
\end{tabular}




\begin{tabular}{|c|c|}
\hline discriminación & $\begin{array}{l}\text { la esfera de la vida y salud } \\
\text { reproductiva. }\end{array}$ \\
\hline $\begin{array}{l}\text { El derecho al matrimonio y a fundar } \\
\text { una familia }\end{array}$ & $\begin{array}{l}\bullet \text { El derecho de las mujeres a decidir } \\
\text { sobre cuestiones relativas a su } \\
\text { función reproductora en igualdad y } \\
\text { sin discriminación. • El derecho a } \\
\text { contraer o no matrimonio. • El } \\
\text { derecho a disolver el matrimonio. • } \\
\text { El derecho a tener capacidad y edad } \\
\text { para prestar el consentimiento para } \\
\text { contraer matrimonio y fundar una } \\
\text { familia. }\end{array}$ \\
\hline El derecho a la educación & $\begin{array}{l}\text { - El derecho a la educación sexual y } \\
\text { reproductiva. • El derecho a la no } \\
\text { discriminación en el ejercicio y } \\
\text { disfrute de este derecho. }\end{array}$ \\
\hline $\begin{array}{l}\text { El derecho a la información adecuada } \\
\text { y oportuna }\end{array}$ & $\begin{array}{l}\text { - El derecho de toda persona a que se } \\
\text { le dé información clara sobre su } \\
\text { Estado de salud. • El derecho a ser } \\
\text { informada sobre sus derechos y } \\
\text { responsabilidades en materia de } \\
\text { sexualidad y reproducción y acerca } \\
\text { de los beneficios, riesgos y } \\
\text { efectividad de los métodos de } \\
\text { regulación de la fecundidad y sobre } \\
\text { las implicaciones de un embarazo } \\
\text { para cada caso particular. }\end{array}$ \\
\hline $\begin{array}{l}\text { El derecho a disfrutar del progreso } \\
\text { científico y a dar su consentimiento } \\
\text { para ser objeto de experimentación }\end{array}$ & $\begin{array}{l}\text { - El derecho a disfrutar del progreso } \\
\text { científico en el área de la } \\
\text { reproducción humana. } \\
\text { - El derecho a no ser objeto de } \\
\text { experimentación en el área de la } \\
\text { reproducción humana. }\end{array}$ \\
\hline
\end{tabular}

Fuente: Alda Facio, 2008 


\section{ABORTO: DEFINIENDO CONCEPTOS}

Siguiendo a Faúndes y Barzelatto (2011:48), aborto es toda interrupción de un embarazo, la cual puede producirse con o sin intervención externa: en el primer supuesto tendremos aborto inducido, y aborto espontáneo en el segundo. Siempre el aborto inducido es aquel en el cual la interrupción del embarazo obedece a una intervención externa deliberada; en tanto el aborto espontáneo es el que sin ninguna intervención externa puede producirse por enfermedades de la madre o bien por defectos genéticos del embrión.

Establecidos estos conceptos, es necesario distinguir otras situaciones, en particular respecto del aborto inducido; me refiero a aquellas vinculadas con el marco normativo, vale decir a si se encuentra o no previsto en las respectivas legislaciones de cada país; en su caso de qué forma lo ha determinado el creador de la norma -extensión o modalidades, según se trate de un sistema de plazos o de permisión o excepciones-. Asimismo, debemos prestar atención a la interpretación de la ley o de la Constitución del país por parte del poder judicial, y es cuando el concepto o la definición del aborto es plasmado en una sentencia judicial.

También debe considerarse a quiénes realizan los abortos, si son o no profesionales médicos, y de ello síguese la observancia del entorno en que se lleva adelante esta práctica. Según la OMS (2012) el aborto inseguro

"es un procedimiento para finalizar un embarazo no deseado realizado por personas que carecen de la capacidad necesaria o que se lleva a cabo en un entorno donde se carece de un estándar médico mínimo, o ambos."

"El aborto ilegal es el que más posibilidades tiene de ser inseguro, y se define por fuera de los márgenes establecidos en cada Estado como aceptado o permitido; por lo tanto, esa inseguridad surge de no estar "regulado por las normas de salud pública" (Planned Parenthod, 2010: $1)$.

Finalmente, encontramos el aborto restringido por la ley, que "es el aborto que 
se autoriza solamente bajo condiciones específicas que limita el acceso a los servicios" (Planned Parenthod, 2010: 1). De suyo, ello motiva la recurrencia a abortos ilegales, y por tanto inseguros, poniendo en riesgo a una amplia franja de mujeres cuya vulnerabilidad está dada por diversos factores.

La consecuencia más importante de los abortos ilegales y los abortos inseguros - la más dramática dirán Faúndes y Barzelatto- son las muertes de mujeres que deciden terminar con un embarazo en condiciones inseguras muy lejanas a las formas requeridas para ese tipo de intervenciones. (2011: 75). Otro punto a considerar es lo que se conoce como mortalidad materna; según los autores precitados, es: “... la muerte de una mujer durante el embarazo y hasta 42 días después del parto, a raíz de causas relacionadas con el estado de gravidez o agravadas por la gestación." (2011: 75).

\section{LEYES SOBRE ABORTO EN EL MUNDO. SISTEMAS $Y$ MODALIDADES. SITUACIÓN PARTICULAR DE ALGUNOS PAÍSES}

El Centro de Derecho Reproductivos publica desde 1998 el Mapa de Leyes sobre Aborto, material de gran utilidad no sólo para conocer jurídicamente el tema, sino también para "reivindicar el mejoramiento del acceso al aborto legal y en condiciones seguras en todo el mundo." (CRR, 2014).

A julio de 2014 los datos que surgen de dicho material son los siguientes:

1.- Para salvar la vida de la mujer o prohibido totalmente: 66 países, que equivalen al $25,5 \%$ de la población mundial.

2.- Para preservar la salud: 59 países, que equivalen al 13,8\% de la población mundial.

3.- Razones socioeconómicas: 13 países, que equivalen al $21,3 \%$ de la población mundial.

4.- Sin restricciones en cuanto a la razón: 61 países, que equivalen al 39,5\% de la población mundial.

Según el CRR, desde 1994 en adelante, en relación a los países del Norte que incluiría el centro y el este de Asia, puede advertirse la existencia de leyes más liberales en la materia, en contraste con los países del hemisferio sur que tienden a ser más restrictivos. Es en esta última franja donde se ubica nuestro ámbito geográfico de particular atención en el presente trabajo - también África, 
el Medio Oriente y Asia meridional están emparentados con aspectos o situaciones de la región de LAC-.

El CRR sostiene también, tal como lo tiene dicho la Organización Mundial de la Salud, que a mayor restricción en materia de aborto más altas son las tasas de mortalidad materna; vale decir que aún cuando nos enfrentemos con abortos ilegales o inseguros -que son los de mayor riesgo para la salud de las mujeres-, esto no impide que las mujeres ocurran en demanda de servicios de aborto.

En los países de Europa Occidental, las tasas de aborto y de mortalidad materna son muchos más bajas allí donde existen el aborto establecido mediante sistemas de plazo o bien, porque se han diseñado sistemas de permisión muy amplios.

En los escenarios más restrictivos, el aborto se convierte en un recurso para las mujeres con mayor poder económico, que son quienes tienen más posibilidades de sortear los impedimentos legales; en tanto que las mujeres pobres van a poner en riesgo sus vidas como consecuencia de la interrupción de embarazos no deseados. O bien, como sucede en nuestra región de LAC, también ponen en juego su propia libertad personal a raíz de la penalización absoluta del aborto que se traduce en sentencias judiciales que les imponen penas de larga duración.

Una cuestión a tener en cuenta, es la vinculada con el acceso al aborto según el ámbito geográfico de residencia: no es lo mismo la situación de la mujer en los centros urbanos, como el de aquellas otras que habitan lejos de las ciudades, a veces en parajes inaccesibles a cualquier recurso sanitario, y que multiplican de esta forma las dificultades y obstáculos que deben enfrentar las mujeres rurales. En tal sentido, resulta relevante el panorama que nos brinda Regina Tamès, Directora General de Gire (2012) acerca de la morbi mortalidad materna en México, donde el mayor número de muertes corresponde a las mujeres de menos recursos económicos y viven lejos de las grandes ciudades, donde hay escasez de servicios de salud, y los recursos e insumos son inexistentes, y que, cuando hay personal está poco calificado.

Existe una realidad en nuestra región que es el aumento del aborto medicamentoso respecto de países como Brasil, Colombia, Ecuador, México, Perú y República Dominicana, según informa el Instituto Guttmacher (2012). 
En punto a los abortos ilegales y/o inseguros, debe considerarse la situación de los proveedores de dichos medicamentos, según sean estos legales o no seguros. En este sentido, conviene estar alertas -tal como lo señala la OMS- a "las consecuencias de usar ciertos medicamentos, como el misoprostol (un análogo de la prostaglandina)", ya que su administración en dosis incorrectas para inducir el aborto produce efectos diversos, aunque "existe cierta evidencia de que incluso una dosis incorrecta puede producir igualmente una reducción en la cantidad de complicaciones graves y muertes maternas". (OMS.19).

\section{LEYES SOBRE ABORTO EN LATINOAMÉRICA Y EL CARIBE}

En América Latina y el Caribe predomina la despenalización parcial y por causales; por tanto, puede afirmarse que en su mayoría, al menos en treinta países se lo sigue considerando un delito establecido en el código penal, existiendo sistemas de excepción o causales de permisión, siendo éstas referidas a cuando se encuentra en riesgo la vida de la mujer, así como también su salud física o mental, en los casos de inviabilidad extrauterina del feto, y en los supuestos de violación o incesto (Bohórquez Monsalve, 2015: 154).

Cuba, Guyana, México Distrito Federal y Uruguay cuentan con leyes que han liberalizado el aborto, a petición de la mujer. Por su parte, se encuentra totalmente prohibido en El Salvador, Honduras, Nicaragua y República Dominicana. En los restantes países de la región la despenalización es parcial y por causales.

En consecuencia, se podrían establecer los siguientes porcentuales: sólo el 12\% de los países de nuestra región exhiben la despenalización total del aborto; en tanto, la penalización total es casi del 15\%, restando un $73 \%$ que engloba a aquellas naciones en las que nos encontramos con supuestos de permisión o de excepción, que son los abortos por causales. Estos guarismos sirven para dejar en claro la problemática del aborto en la región de LAC, toda vez que las condiciones de acceso a abortos seguros dentro de ese $73 \%$, no es igual para todas las mujeres, como consecuencia de los obstáculos y dificultades que deben enfrentar - a los que me referí precedentemente-. 


\section{1.- El aborto en cifras}

En la región de América Latina y el Caribe, según las cifras que surgen del informe del reconocido Instituto Guttmacher (2012), entre 2003 y 2008 la tasa de aborto se mantuvo relativamente estable, si bien el 95\% de los abortos realizados en la región durante el año 2008 fueron abortos inseguros - tal como los considera la OMS al ser realizados por personas carentes de habilidades para el ejercicio de la profesión médica, o bien que no respetan los estándares médicos mínimos, o ambos-. Existe una realidad que es la de proveedores clandestinos de aborto, lo cual naturalmente no solamente pone en riesgo la salud de las mujeres, sino que además en muchos casos compromete su libertad; también se señala el otro gran riesgo que son los abortos autoinducidos, en los cuales las mujeres recurren a métodos peligrosos, o bien mediante la compra de medicamentos, diferenciando aquellos que se obtienen en farmacias de esos otros que son suministrados por otro tipo de proveedores no seguros. El informe indica que el $12 \%$ de todas las muertes maternas de LAC según datos de la OMS en el año 2008 se debieron a abortos inseguros; mientras que cerca de un millón de mujeres son hospitalizadas anualmente como consecuencia de complicaciones originadas en abortos inseguros; en tanto entre un 10 y un $20 \%$ del total de mujeres que abortan no reciben atención médica cuando sufren complicaciones que sí lo requieren.

Adviértase que, al hablar de cifras y estadísticas en materia de aborto, sólo pueden contabilizarse aquellas que de una forma $u$ otra fueron captadas por efectores públicos o estatales, obviando todo lo que no está registrado, que es invisible a las estadísticas.

Datos más recientes de IPAS Bolivia $(2018,5)$ revelan que

"En América Latina y el Caribe, la cifra absoluta de abortos pasó de 4.4 millones a 6.5 millones, entre los periodos 19901994 y 2010-2014. Asimismo, la tasa de abortos por cada 1000 mujeres de 15 a 44 años, subió de 40 a 44." 


\section{2.- La interpretación de las distintas causales según los operadores de los sistemas de salud}

El alcance o interpretación que se le da, por parte de los operadores de los sistemas de salud, a las distintas causales, o excepciones a la regla general de penalización del aborto, deviene en muchísimos casos en obstáculos, que en ocasiones, impiden la práctica según lo prevén las respectivas leyes. Amorós (2014: 36) claramente indica que el sistema de plazos es el más recomendable criterio que comparto-, puesto que, de otra forma, las mujeres quedamos expuestas a la interpretación del alcance y extensión de cada una de las causales que hagan los proveedores sanitarios. Ello así, sin contar con la mayor o menor predisposición de aquellos, en la aplicación de los reglamentos o protocolos sanitarios para llevar adelante abortos seguros, en los supuestos permitidos por la ley. He aquí que encontramos otro escollo fundado en la objeción de conciencia, situación ésta no siempre adecuadamente resuelta por las autoridades correspondientes.

\subsection{1.- Objeción de conciencia}

Soledad Deza (2014) autora especializad en DSR, integrante de Católicas por el Derecho a Decidir, Argentina, desvela con meridiana claridad que quienes resultan objetores de conciencia no son médicos/as deseosos de profesar libremente su culto, y que no debemos suponer que su obrar nos muestra conductas asépticas; hacerlo sería absolutamente ingenuo de nuestra parte. Para esta autora "Objetar de conciencia en materia de prácticas médicas no reproductivas, es una conducta que invade la autonomía de las mujeres como agentes morales y que irradia a otras, un modelo de vida." (227).

La Unión Europea no es ajena a esta problemática; de suyo el Informe sobre salud sexual y reproductiva y derechos afines -conocido por el nombre de su ponente Edite Estrela - presentado al Parlamento Europeo en 2013, no ha logrado su aprobación. Claramente se denuncia allí que

"La práctica de la objeción de conciencia ha denegado a muchas mujeres el acceso a los servicios de salud reproductiva, como información, acceso y compra de anticonceptivos, análisis prenatales e interrupción legal del embarazo. Se han mencionado casos de 
Eslovaquia, Hungría, Rumanía, Polonia, Irlanda e Italia donde cerca del $70 \%$ de todos los ginecólogos y el $40 \%$ de todos los anestesistas se oponen a prestar servicios de aborto por motivos de conciencia. Estas barreras contravienen claramente las normas de derechos humanos y las normas médicas internacionales."

Si esto sucede en una región en la que la mayoría de los países cuentan con leyes permisivas de aborto, con unas pocas excepciones, fácil resulta concluir la incidencia que en la región de LAC tiene esta práctica.

\subsection{2.- Violación del secreto médico. Deber de Confidencialidad.}

Existe otro escollo para las mujeres que han tomado la decisión de abortar, o aún aquellas que llegan a los hospitales con un aborto en curso -que puede ser espontáneo, tanto como derivado de complicaciones obstétricas por haberse sometido a un aborto ilegal-, que es la violación del secreto profesional, y el no acatamiento al deber de confidencialidad al que deberían sujetarse los prestadores de los servicios de salud. En tales circunstancias se conforma un dueto -violación de secreto y deber de confidencialidad- que puede llegar a ser mortal para las mujeres.

"Cuando una mujer en estado de vulnerabilidad acude a un hospital público en busca de asistencia vital que le permita poner a salvo su vida e integridad personal, la sola posibilidad de ser interrogada, tratada, seleccionada y denunciada como sospechosa de un delito por el personal sanitario que debiera asistirla la convierte en un blanco fácil de apresar para el sistema penal, circunstancia ésta que a su vez la coloca frente al dilema de decidir entre su propia muerte o la pérdida de su libertad." (Deza 2013:54).

El informe de IPAS $(2016,12)$-centrado específicamente en este tema-, rebela en forma alarmante la creciente tendencia de los profesionales de la salud a no cumplir con el deber de confidencialidad respecto de sus pacientes, aumentando en consecuencia el temor de las mujeres que acuden a los servicios de salud ante complicaciones de un aborto inducido o inseguro. Así, los sistemas de salud se convierten en el punto de "acceso" a la justicia, el cual mayoritariamente - es notoriamente arbitrario y violatorio de los derechos de las mujeres. 
Datos recientes de una encuesta realizada en Brasil durante el año 2017, da cuenta de que en 18 estados de los 26 que integran la unión brasileña más el Distrito Federal, se registraron 331 procesos por la práctica del autoaborto; entendido que esta figura remite al aborto provocado por la gestante o con su consentimiento tal como está tipificado en el artículo 124 del Código Penal.flA tono con el tópico que vengo tratando, lo que surge es que una parte importante de esos procesos son consecuencia de las denuncias de profesionales de la salud, al tomar conocimiento que las mujeres acudían a la atención de emergencia para tratar una complicación. ${ }^{1}$

Las mujeres, en las condiciones que vengo mencionando, no sólo ponen en juego su salud, y aún sus propias vidas, sino que en muchos casos deben enfrentar la pérdida de su libertad, sometidas a procesos penales, que en algunos casos pueden derivar en condenas muy rigurosas.

\section{3.- Casos que por sus singularidades ejemplifican la realidad de la región. Las leyes, su interpretación, y la jurisprudencia, como herramientas para la transformación del derecho vigente.}

\subsubsection{El derecho no es neutro}

En este punto intento plantear mediante casos particulares, de qué manera la ley, su interpretación y las sentencias de los tribunales de justicia pueden ampliar o restringir los derechos sexuales y reproductivos, partiendo de la premisa que el Derecho como ciencia no es neutro, que su producción es androcéntrica, que el modelo de lo humano ha sido y sigue siendo el hombre, y que los derechos humanos de las mujeres, a pesar de los avances legislativos y aún más a partir de los estándares provenientes del derecho internacional, todavía constituyen declaraciones de igualdad formal, en tanto que la real queda encorsetada en los textos de las disposiciones normativas, cuando no por la extensión o alcance que hacen de ellos los tribunales, y otros operadores gubernamentales.

Alda Facio, como jurista feminista se ha ocupado del valor del lenguaje, por lo que sus palabras son muy ilustrativas en punto a qué dicen las leyes, cómo

\footnotetext{
${ }^{1}$ La encuesta producida por Portal Catarinas en asociación con GHS Brasil también examinó el número de procesos inducidos por otros abortos tipificados en los artículos 125 (sin el consentimiento de la mujer embarazada) y 126 (con el consentimiento de la mujer embarazada). Disponible en http://catarinas.info/brasil-registra-um-processo-por-autoaborto-todo-dia/\#.WuyScISb4YY.twitter
} 
dicen lo que dicen, y qué podemos esperar de ellas:

"Como sólo los hombres/varones han tenido el poder de definir las cosas, todo lo que está definido lo está desde su perspectiva únicamente. Si sólo los hombres han tenido el poder de definir, sólo ellos han conformado la cultura y por ende, esta cultura es masculina. En otras palabras, las mujeres como seres humanos plenos, no existimos en esta cultura. No podemos contentarnos con incorporarnos a esta cultura ya definida por y para el hombre, porque en ella nunca podremos existir plenamente ni como mujeres ni como "seres humanos neutrales en términos de género" cosa que pretenden ingenuamente algunas mujeres."

La legislación en tanto producción normativa ejemplifica lo que nuestra autora afirma; es por ello que las mujeres batallamos por ser parte de las legislaturas mediante la recurrencia a medidas de acción afirmativa, como es el sistema de cupo femenino.

\subsection{2.- El derecho a elegir y ser elegidas. El sistema de cuotas.}

El derecho al voto de las mujeres fue una conquista que llegó a nuestra región algunas décadas después que en Europa. Sin embargo, para romper con la tematización del derecho androcéntrico, las mujeres no sólo tenemos que gozar del derecho a elegir, sino también, el derecho a ser elegidas.

La Convención Interamericana Sobre Concesión de los Derechos Políticos a la Mujer, adoptada el 5 de febrero de 1948, fue ratificada por 24 Estados, no siendo signatarios de la misma Antigua y Barbuda, Bahamas, Barbados, Bélize, Grenada, Jamaica, Santa Lucía, St. Vicente y Grenadines y Trinidad y Tobago. Si bien esta convención nos abrió la puerta al voto, lo que nos permitió fue elegir sólo varones, a pesar de lo postulado por este instrumento que establecía que el voto no podía negarse o restringirse por razones de sexo. Tendrían que pasar algunas décadas para lograr el objetivo de ser elegidas, a partir de los noventa en que comenzó a legislarse sobre el cupo femenino. Según indicadores utilizados por la Cepal (2017) nuestra región sigue a la cabeza mundial en cuanto a la presencia de mujeres en los órganos legislativos, alcanzando un promedio del 28,8\%, encontrándose el Caribe por debajo de ese guarismo, toda vez que la participación de las mujeres en los parlamentos sólo alcanza al 16,9\% 
en promedio.

¿Esto nos dice algo cuando hablamos del derecho al aborto? En mi opinión, sí, aunque no es la única variable a considerar. El ejemplo más notorio es el de Nicaragua donde el aborto está prohibido y sin embargo ostenta un curioso $40 \%$ de participación femenina, al igual que Cuba, donde sí el aborto está despenalizado totalmente. Por su parte, países donde el aborto está despenalizado parcialmente como Haití y Bélice no alcanzan el 10\% de representación femenina en sus órganos legislativos. La gráfica siguiente permite ilustrar la situación regional en la materia.

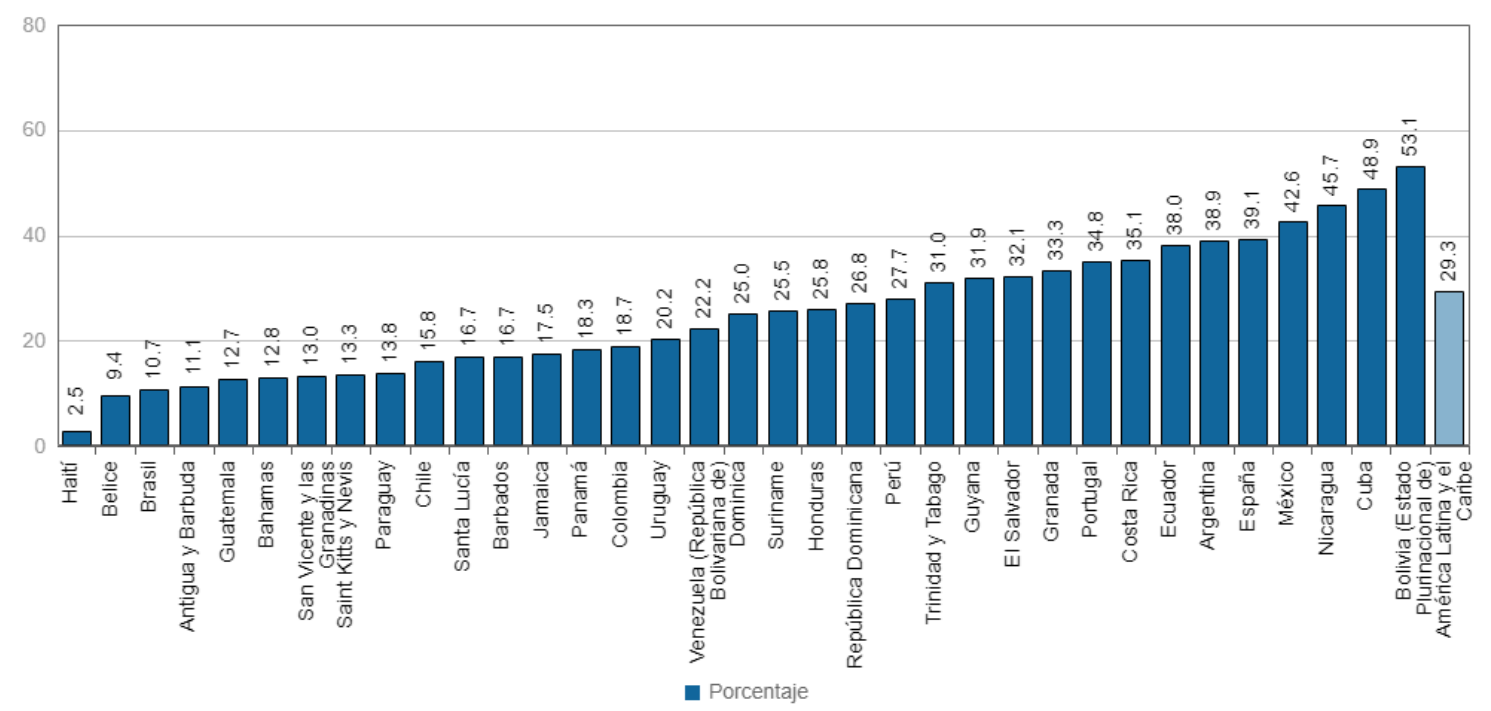

Fuente https://oig.cepal.org/es/indicadores/poder-legislativo-porcentaje-mujeres-organolegislativo-nacional-camara-baja-o-unica

Una primera aproximación a la lectura que puede hacerse es la relativa al funcionamiento de los partidos políticos, de una parte, los regímenes electorales utilizados de otra, y finalmente si los sistemas de cuotas funcionan adecuadamente en todos los países que los han adoptado. Aunque ahondar en profundidad en estos supera las posibilidades del presente estudio, voy a señalar algunas particularidades que ofrece la región en la aplicación del sistema de cuotas.

Según el Observatorio de Igualdad y Género de América Latina y el Caribe la participación femenina en las legislaturas viene creciendo en forma sostenida en las últimas dos décadas, precisamente a partir de la implementación de las cuotas de género; merced a ello hay un cambio notorio en la desigualdad desde lo cuantitativo. Las cuotas ayudan, pero no resuelven el problema de la 
infrarrepresentación femenina, Tomemos por ejemplo Brasil, donde las mujeres son relegadas a los últimos lugares de las listas, por cuanto su representación equivale al 8,80\%; también tenemos el caso de Panamá donde la cuota es sólo del $10 \%$ pero no tiene carácter obligatorio y por tanto no se sanciona su incumplimiento.

Sin embargo, dos países que no tienen cuotas como Uruguay y Chile, han sancionado sendas leyes de interrupción voluntaria del embarazo; el primero de ellos despenalizando el aborto dentro de las primeras doce semanas además de las causales para ciertos supuestos-, y el segundo estableciendo la despenalización por causales.

¿Entonces, dejamos de lado el sistema de cuotas? Mi respuesta es no; debemos seguir impulsándolas hasta alcanzar la paridad, 50 y 50, no sólo en las listas electorales, sino en los estatutos de los partidos políticos. Asimismo, es necesario rever los distintos regímenes electorales, pues según los distintos tipos que se utilicen puede suceder que al final, reduzcan la representación femenina.

\subsubsection{Presentación de casos elegidos por sus singularidades}

En este acápite pretendo mostrar la versatilidad de los regímenes legales de la región, a partir de la respuesta estatal, tomando algunos ejemplos de países, en un abanico que va desde la prohibición absoluta hasta la permisión del aborto mediante el sistema de plazos, incluyendo los casos de causales o de excepción a la criminalización de la práctica de interrupción voluntaria del embarazo.

\subsubsection{1.- En El Salvador rige la penalización absoluta del aborto, y su código} penal exhibe uno de los sistemas más rigurosos para las mujeres, por la extensión de las penas que se imponen como condena. La sociedad civil informa que unas 25 mujeres están encarceladas, cumpliendo condenas que van desde 11 hasta 40 años de prisión, en tanto existen cientos de ellas sometidas a procesos penales. Son mujeres que sufrieron complicaciones obstétricas y falta de atención médica, y a consecuencia de ello abortaron; por tal motivo fueron condenadas por homicidio agravado.

A pesar de todos los reclamos intentados, incluida la petición de indulto para 
algunas de aquellas, sólo una de ellas fue favorecida mediante esta acción en enero de 2015 - este es el caso de Guadalupe, quien sufrió un aborto involuntario a los 18 años tras haber sido violada y fue condenada a 30 años de prisión en febrero de 2008-.

Recientemente, y luego de una larga batalla legal, y una intensa campaña internacional, otra mujer de nombre Teodora recuperó su libertad, tras pasar diez años encarcelada, como consecuencia de la condena de 30 años de prisión que le fue impuesta a causa de haber sufrido la pérdida de su embarazo en 2007, mientras estaba trabajando. Su libertad es producto de la conmutación de la condena, dispuesta por el Ministerio de Justicia de El Salvador, sin que se anule ni su culpabilidad ni se reconozca su inocencia.

5.3.4.2.- En Paraguay la única causal de exención de responsabilidad penal es cuando la vida de la mujer esté amenazada, pero no existe reglamentación que explicite cuáles son los casos considerados como peligro serio de la vida de la madre. Como referencia he tomado el caso de Mainumby -nombre ficticio con el que en 2015 trascendió mundialmente - quien tenía diez años de edad cuando quedó embarazada como consecuencia de una violación. A pesar del intenso activismo que despertó el caso, la justicia hizo caso omiso de la petición de interrumpir la gestación, a consecuencia de lo cual el Estado recluyó a la niña, encarceló a la madre acusada de negligencia, y obligó a la niña parir a pesar del riesgo que ello implicaba para su salud.

El análisis del caso demuestra que tanto las disposiciones de la CEDAW, como las de la Convención de Belén do Pará, fundamentalmente, han sido violadas por el Estado paraguayo, incumpliendo las obligaciones asumidas con su ratificación.

5.3.4.3.- En Colombia, hace doce años la Corte Constitucional -caso C-355sentenció que la prohibición total del aborto es inconstitucional, disponiendo que el aborto fuera legal y accesible en algunos supuestos. A nivel regional se reconoce esta sentencia como histórica, pues es la primera vez que se tratan los derechos sexuales y reproductivos de las mujeres como derechos humanos. En este decisorio la Corte sostuvo que el aborto es un derecho fundamental y que no puede ser criminalizado en los supuestos de violación o incesto, inviabilidad fetal por malformaciones, y cuando la vida o la salud de la mujer esté en peligro 
como consecuencia de un embarazo. ${ }^{2}$

Mónica Roa -entonces una muy joven y brillante abogada- fue la artífice de este salto cualitativo en el derecho colombiano, mediante la presentación de una demanda de inexequibilidad ante la Corte Constitucional, el 14 de abril de 2005. El caso puso a prueba la modalidad del litigio estratégico como una forma de activismo para generar cambios en el sistema de justicia y que sus resultados impacten en la sociedad. ${ }^{3}$

5.3.4.4. En México, a excepción del Distrito Federal, el aborto está restringido por causales, variando entre los Estados la forma en que se interpretan unas u otras.

Marimar tenía 17 años cuando concurrió al hospital solicitando la interrupción del embarazo. El Comité de Bioética del hospital resolvió negarle su derecho pese a que el aborto es legal en casos de violación en todo el país, determinando que debía continuarse la gestación. En febrero de 2016 se entabló una demanda de amparo contra el hospital, y ante la no resolución del juez de la causa, se interpuso un recurso que llevó el caso ante la SCJN. ${ }^{4}$

La decisión de la Suprema Corte de Justicia de la Nación de México por unanimidad de la Sala Segunda, causó notoriedad por estos días, al reconocer en su sentencia del 4 de abril de 2018, que las violaciones a los derechos humanos de una menor de edad, a quien se le negó un aborto producto de una violación sexual, constituyen una violación a sus derechos reproductivos, imponiendo una reparación en favor de ella y de su familia, de manera oportuna, integral y efectiva.

La cuestión adquiere una gran dimensión, por cuanto tal como la ha informado GIRE $(2017,9)$ persisten los obstáculos para la ILE en casos de violación, ya que

"Desde el año 2013, con la entrada en vigor de la Ley General de Víctimas, se eliminaron del marco legal los requisitos para víctimas de delitos y de violaciones a los derechos humanos para acceder al aborto legal. ... aun cuando la ley así lo indica, el desconocimiento de las

\footnotetext{
${ }^{2}$ Fuente: https:/ / www.reproductiverights.org/press-room/10-years-of-legal-abortion-in-colombia

${ }^{3}$ Fuente: http:/ / www.mujeresenred.net/spip.php?article1292e

${ }^{4}$ Fuente: https:/ / gire.org.mx/gana-caso-en-la-scjn-menor-a-quien-se-le-nego-la-interrupcion-legal-delembarazo-despues-de-sufrir-violencia-sexual/
} 
obligaciones de los prestadores de salud, o el afán de imponer sus creencias personales por encima de la salud y, en ocasiones, la vida de las niñas y mujeres sigue siendo un obstáculo para que ellas accedan a los derechos mínimos que les permitan recuperarse de esta situación de violencia y un embarazo que nunca debieron enfrentar." ${ }^{\prime 5}$

5.3.4.5.- Chile contaba con una ley de 1931 que legalizaba el aborto en ciertas circunstancias, la cual fue modificada en 1989 prohibiendo la práctica en todos los casos, aún cuando corriera riesgo la salud de la mujer. La sanción de la nueva ley fue impulsada por la presidenta Bachelet en enero de 2015, y contó con el apoyo de amplios sectores sociales, de organizaciones de mujeres, así como de expertos internacionales y regionales. Se trata de una norma que despenaliza el aborto por tres causales: cuando la vida de la mujer corra peligro, cuando el embarazo sea producto de una violación, y cuando el feto sufra malformaciones incompatibles con la vida extrauterina. Fue un largo y arduo proceso, el cual inclusive concluyó con una sentencia del Tribunal Constitucional toda vez que sancionada la ley, los grupos conservadores interpusieron una acción de inconstitucionalidad. Pese al ajustado resultado -6 a 4- la sentencia permitió finalmente la promulgación de la ley.

\section{4.- Dictámenes de organismos internacionales que han condenado la violación de los derechos sexuales y reproductivos}

Los casos elegidos involucran a países con similar postura en materia de aborto, unos poseen legislación que lo despenaliza parcialmente mediante causales, otros donde la prohibición es absoluta. La selección permite arrojar una luz distinta sobre el tópico, e involucran las dificultades y obstáculos que los sistemas conllevan -estereotipos, resistencias de los efectores de salud, criterios limitados sobre la interpretación y alcance del derecho al aborto, entre otras cuestiones-.

\section{Argentina}

El caso de LMR oportunamente fue presentado ante el Comité de Derechos Humanos de Naciones Unidas alegando que se habían violado los derechos contenidos en los artículos 2, 3, 6, 7 y 18 del Pacto Internacional de Derechos Civiles y Políticos.

\footnotetext{
${ }^{5}$ Fuente: http:/ / aborto-por-violacion.gire.org.mx/assets/pdf/violencia_sin_interrupcion.pdf
} 
LMR de 19 años y una edad mental de entre 8 y 10 años quedó embarazada como consecuencia de los abusos sexuales de un tío. Aunque la madre solicitó que se le practicara un aborto legal en el hospital de su localidad, en la Provincia de Buenos Aires, le fue denegado y dispuesto el traslado a otro centro de salud. Cuando la intervención estaba a punto de concretarse fue interrumpida por orden de una jueza de menores, iniciándose allí un proceso judicial que llegó al superior tribunal local, el cual ratificó la constitucionalidad del artículo 86 del Código Penal Argentino, por el cual el aborto era no punible. No obstante, esta sentencia, el hospital se negó a realizar el aborto invocando el avanzado estado de embarazo de LMR. Grupos fundamentalistas desplegaron fuertes presiones tendientes a impedir la intervención médica, suponiéndose que aquellos habrían influido con su accionar en la decisión de los profesionales de la salud. Finalmente, la situación debió resolverse - al impulso y acompañamiento del movimiento de mujeres- en el circuito clandestino con el riesgo que esto suponía.

El dictamen del Comité de Derechos Humanos de Naciones Unidas (2011) es muy importante, no sólo para nuestra región, sino que impacta muy positivamente respecto de los derechos de las mujeres a nivel mundial, pues es la primera vez que se establece que, a tenor del artículo 3 del Pacto, la negativa al aborto legal resulta violatoria del derecho a la igualdad entre varones y mujeres en el goce de los derechos civiles y políticos. Asimismo, se afirma que en el caso se incurrió en trato cruel, inhumano y degradante violando de este modo las previsiones del artículo 7; y, en línea a lo que he señalado respecto a la cuestión de la violación de secreto profesional, el Comité afirmó que se violó el derecho a la privacidad de LMR, a tenor de lo establecido en el artículo 17, ya que la cuestión no debió exceder los límites de la relación médico-paciente.

\section{Brasil}

El caso de Alyne fue el primer caso en que un organismo internacional abordó la mortalidad materna como una cuestión de derechos humanos. Mujer afrobrasilera, a los 28 años murió ante la negativa del sector público y privado de proporcionarle servicios de calidad de salud materna ante las complicaciones que tuvo durante su embarazo. En el abordaje de este caso el Comité CEDAW reconoció en 2011 que los estados están obligados de forma inmediata para hacer cumplir los derechos humanos, lo que incluye reducir la mortalidad materna, así como fortalecer el sistema de reconocimiento de los derechos 
reproductivos como obligaciones inmediatas del Estado. Asimismo, consideró que la prestación de servicios de calidad de salud materna debe ser ofrecida sin discriminación, sin importar, la raza, los ingresos o la ubicación geográfica de sus destinatarias.

\section{Costa Rica}

La sentencia 2000-02306 de 15 de marzo de 2000, dictada por la Sala Constitucional de Costa Rica, prohibió la práctica de la fecundación in vitro, al declarar la inconstitucionalidad del Decreto Presidencial 24029-S, del 3 de febrero de 1995. Denunciado el Estado ante la CIDH, finalmente el 28 de noviembre de 2012, la Corte Interamericana de Derechos Humanos estableció que el embrión humano no es una persona, así como también brinda su interpretación del artículo 4.1 del Pacto, que dice: “Toda persona tiene derecho a que se respete su vida. Este derecho estará protegido por la ley y, en general, a partir del momento de la concepción. Nadie puede ser privado de la vida arbitrariamente."

La causa Artavia Murillo y Otros Vs. Costa Rica es de gran trascendencia pues reconoce el derecho a procrear, y el derecho a no procrear; es decir establece que los derechos reproductivos son derechos humanos. También es destacable lo afirmado con relación a los métodos contraceptivos, y la viabilidad de la tan debatida pastilla del día después, que constituye un reconocido y eficaz mecanismo de emergencia; la sentencia expresa que en ninguno de estos supuestos es posible hablar de métodos abortivos, pues si estamos en presencia de un embrión, no hay concepción alguna.

Por último, también la CorteIDH afirma que la prohibición de la FIV afecta los derechos a la vida privada y familiar, los derechos reproductivos y la integridad personal; y amplía en el sentido que el derecho a la vida privada está estrechamente vinculado a 1.- el derecho a la familia, 2.- la autonomía reproductiva, y 3.- el acceso a servicios de salud reproductiva, con derecho a la posibilidad de acceder a la mejor tecnología en la materia.

\section{Haití}

Las mujeres se vieron especialmente vulneradas después del terremoto de 2010, no sólo porque debieron desplazarse a los campamentos, sino porque la vida en ellos exacerbó los de por sí altos índices de violencia sexual, y aunque 
reportaban los ataques, éstos no eran tenidos en cuenta por los servicios de seguridad.

Además de las carencias básicas, tampoco existía el acceso a servicios de salud, por lo que las víctimas de agresiones sexuales no contaban ni con profilaxis de VIH ni mucho menos anticoncepción de emergencia.

En tales condiciones Women's Link Wordwide, en unión con otras organizaciones, ocurrió ante la CIDH solicitando medidas cautelares "con el objetivo de salvaguardar la integridad física y psíquica de las mujeres y niñas residentes en campos para personas desplazadas internas". ${ }^{6}$ Con excepción del acceso a la interrupción voluntaria del embarazo, la Comisión ordenó un conjunto de medidas cautelares relativas a la atención médica y psicológica, asegurando en particular la privacidad durante los exámenes de las víctimas de violencia sexual, disponibilidad de personal médico femenino, profilaxis contra el VIH, y anticoncepción de emergencia. Asimismo, se dispuso implementar medidas de seguridad en los 22 campamentos, asegurar la capacitación del personal a cargo de las denuncias, así como promover la creación de unidades especializadas para la recepción y la investigación de las denuncias, mandando también que las mujeres de los campamentos lideraran la planificación de medidas y políticas para combatir la violencia sexual, su prevención, y también respecto de otros tipos de violencia.

Estas medidas, si bien no fueron cumplidas en su totalidad por el gobierno, supusieron un avance en el abordaje de los derechos reproductivos de las mujeres y niñas haitianas, con un enfoque de salud amplio e integral, llegando incluso a que organizaciones locales plantearan ante las autoridades la necesidad de revisar la prohibición del aborto en el país.

\section{Honduras}

Es uno de los cuatro países de la región donde la prohibición del aborto es absoluta. La vida política de esta república siempre estuvo afectada por diversos vaivenes político institucionales, incluído un golpe de estado en 2009. Y señalo esto porque cuando de derechos de las mujeres hablamos, también cuenta la calidad democrática, y un concepto amplio de ciudadanía. ${ }^{7}$ Baste

\footnotetext{
${ }^{6}$ Fuente: http:/ / www.womenslinkworldwide.org/informate/publicaciones

${ }^{7}$ El presidente Hernández obtuvo la reelección en 2017 merced a un fallo de la Corte Suprema de Justicia, toda vez que la Constitución de Honduras lo prohibía. Expertos y observadores internacionales han
} 
señalar que bajo el primer mandato del actual presidente se reformó la Constitución que precisamente no permitía la reelección.

En este contexto, entonces, resulta oportuno recurrir al informe de la CIDH sobre la "Situación de los derechos humanos en Honduras" emitido en 2015 -es decir durante la presidencia del ahora reelecto presidente-. La Comisión dijo que las mujeres representan el $52 \%$ de la población de ese país, no obstante lo cual existe una considerable desigualdad tanto en los ámbitos civil, político, económico y social, que impide el pleno disfrute de los derechos humanos de las mujeres y niñas hondureñas, tal como ya lo hubiera ya expresado la Relatora Especial de Naciones Unidas sobre la violencia contra la mujer, sus causas y consecuencias, en su informe de 2011. Por tanto, entendiendo que las mujeres sufren múltiples violencias, y que ello está en la base de la desigualdad y estereotipos existentes en la sociedad, el informe expresa la preocupación de la Comisión respecto de las limitaciones que deben enfrentar aquellas en el ejercicio de sus derechos sexuales y reproductivos. Uno de los tópicos bajo análisis, también, fue la información recibida respecto "del impacto que tiene la prohibición de la anticoncepción de emergencia adoptada en 2009, incluso en casos de violación."

En consecuencia, la Comisión instó a Honduras en el sentido de revisar sus políticas públicas, con el objetivo de modificar los estereotipos sobre el rol de las mujeres tanto en la sociedad como en el seno de las familias, aconsejando la creación de mecanismos de empoderamiento de las mujeres, y en relación con la salud, la CIDH insta al Estado "a garantizar el acceso a servicios de salud reproductiva sin discriminación, con el fin de garantizar el disfrute de sus derechos sexuales y reproductivos."

\section{Nicaragua}

El gobierno de Daniel Ortega, aliado con las iglesias, prohibió el aborto en forma absoluta en el año 2006. Esta situación fue puesta de manifiesto en el año 2009 por el Comité contra la Tortura en el Informe de los Estados, en los términos que transcribo:

"El Comité urge al Estado parte a que revise su legislación en materia de aborto, tal como fue recomendado por el Consejo de Derechos

objetado dichas elecciones -incluida la Unión Europea-, pese a lo cual Hernández asumió la titularidad del Poder Ejecutivo en enero del presente año. 
Humanos, el Comité para la Eliminación de la Discriminación contra la Mujer y el Comité de Derechos Económicos, Sociales y Culturales en sus últimas observaciones finales, y a que estudie la posibilidad de prever excepciones a la prohibición general del aborto para los casos de aborto terapéutico y los embarazos resultantes de violación o incesto. De conformidad con las directivas de la Organización Mundial de la Salud, el Estado parte debe garantizar el tratamiento inmediato y sin condiciones de las personas que buscan atención médica de emergencia. Asimismo, el Estado parte debe evitar penalizar a los profesionales de la medicina en el ejercicio de sus responsabilidades profesionales."

De haberse seguido las recomendaciones del Comité, quizás Amelia no hubiera muerto en 2010, al negársele un aborto terapéutico, que le hubiera permitido acceder a un tratamiento adecuado contra el cáncer que padecía. Los profesionales médicos al comprobar el estado de embarazo de Amelia no sólo le negaron el tratamiento médico para el cáncer, sino que tampoco accedieron al aborto terapéutico ante el temor de ser penalizados.

El caso fue llevado a la CIDH, y ésta proveyó medidas cautelares, en mérito a las cuales el Estado se vio obligado a proveerle un tratamiento a Amelia, mientras seguía cursando su embarazo. No obstante ello, el feto nació muerto, y poco tiempo después también moría Amelia.

\section{Perú}

L.C., de 13 años de edad, víctima de violación, intentó suicidarse al saber que estaba embarazada, y como consecuencia de ello quedó gravemente discapacitada. Le fue negado el aborto terapéutico y tampoco se le practicaron las intervenciones médico-quirúrgicas que exigía su salud con fundamento en su gravidez, en lugar de priorizar su estado de salud física y mental. Pese a que su representante legal había solicitado la interrupción del embarazo, fue sólo después de que L.C. tuviera un aborto espontáneo que los médicos estuvieron dispuestos a realizarle la cirugía. L.C. fue operada casi tres meses y medio después de que se decidiera la necesidad de la intervención.

En el año 2009 el Comité para la Eliminación de la Discriminación contra la Mujer (CEDAW) condenó a Perú por violar los derechos humanos de una mujer 
adolescente que requería servicios legales de aborto en el país, y determinó que el Estado debe establecer un mecanismo para el acceso efectivo al aborto terapéutico, establecer condiciones que protejan la salud física y mental de las mujeres, de modo que se impida que en el futuro se produzcan violaciones similares a las del presente caso.

La decisión del Comité se refiere específicamente a violaciones al derecho a la salud sin discriminación, a la obligación de eliminar estereotipos de género y al derecho de acceder a mecanismos efectivos frente a la vulneración de los derechos. También dispuso que el Estado peruano indemnizara y asistiera a la niña de forma de acceder a un adecuado tratamiento para su rehabilitación; que adoptara mecanismos efectivos para el acceso al aborto terapéutico modificando la interpretación restrictiva del mismo; que adoptara directrices o protocolos para garantizar la disponibilidad y el acceso de servicios públicos de salud reproductiva para las/los adolescentes; $y$, finalmente, que revisara la legislación que criminaliza a las mujeres que interrumpen sus embarazos producto de una violación.

\section{República Dominicana}

El aborto está prohibido en todas sus formas. En el marco de las dificultades que este país enfrenta hace décadas respecto de la nacionalidad de los hijos de haitianos nacidos en su territorio, la CIDH produjo un informe en el año 2015, denominado "Situación de los derechos Humanos en Honduras", alentando al Estado Dominicano a observar sus recomendaciones en punto a garantizar el goce efectivo de los derechos humanos de todas las personas en su territorio, conforme las obligaciones internacionales en materia de derechos humanos-. En lo que aquí interesa, en especial, su recomendación fue:

"Adoptar medidas positivas para eliminar la discriminación racial y garantizar y garantizar que las personas dominicanas de ascendencia haitiana, los afroamericanos y los migrantes haitianos accedan a los servicios básicos en condiciones de igualdad en relación con el resto de la población. En particular adoptar medidas positivas orientadas a garantizar un acceso efectivo a servicios de salud, salud materna $y$ reproductiva, vivienda, educación y trabajo." 


\section{LOS DERECHOS SEXUALES Y REPRODUCTIVOS. DÓNDE ESTAMOS, HACIA DÓNDE VAMOS}

El siguiente cuadro que resume la situación de LAC según los distintos regímenes que mencioné al inicio.

\begin{tabular}{|c|c|c|}
\hline Despenalización total & $\begin{array}{c}\text { Despenalización parcial y por } \\
\text { causales }\end{array}$ & Penalización total del aborto \\
\hline 1. Cuba & 1. Antigua y Barbuda & 1. El Salvador \\
\hline 2. Guyana & 2. Argentina & 2. Honduras \\
\hline 3. Uruguay & 3. Bahamas & 3. Nicaragua \\
\hline \multirow[t]{21}{*}{ 4. México D.F. } & 4. Barbados & 4. República Dominicana \\
\hline & 5. Bélice & \\
\hline & 6. Bolivia & \\
\hline & 7. Brasil & \\
\hline & 8. Colombia & \\
\hline & 9. Costa Rica & \\
\hline & 10. Chile & \\
\hline & 11. Dominicana & \\
\hline & 12. Ecuador & \\
\hline & 13. Granada & \\
\hline & 14. Guatemala & \\
\hline & 15. Jamaica & \\
\hline & 16. México & \\
\hline & 17. Panamá & \\
\hline & 18. Paraguay & \\
\hline & 19. Perú & \\
\hline & 20. San Vicente y Las Granadinas & \\
\hline & 21. Santa Lucía & \\
\hline & 22. Surinam & \\
\hline & 23. Trinidad y Tobago & \\
\hline & 24. Venezuela & \\
\hline
\end{tabular}

Fuente: Bohórquez Monsalve, con correcciones de mi autoría.

La variedad de tópicos abordados brinda un panorama que ilustra la situación de la región, mostrando sus singularidades en cuanto al aborto, bastante compleja, por cierto.

También es necesario señalar que la región de LAC es la más desigual del mundo, y donde 10 de los 15 países más desiguales del mundo son latinoamericanos, y el 10\% de la población acapara el 71\% de la riqueza, según el informe sobre la Pobreza de la CIDH (2017). En esta cartografía las mujeres somos sobrevivientes, y las élites gobernantes no están dispuestas a invertir en nuestra salud, ya que ese es también uno de los ejes, cuando hablamos de la legalización del aborto, destinar presupuestos para educación sexual, para proveer métodos anticonceptivos, para prevenir la mortalidad materna, y en 
definitiva para proveer abortos legales y seguros.

Los casos incluidos en el presente, son sólo son una muestra pequeña de cómo se violan los derechos sexuales y reproductivos de las mujeres en nuestra región de LAC. Discriminación, desigualdad, pobreza, raza, lugar de residencia, situación económica, son sólo algunas de las variables que signan la autonomía física de las mujeres. También la prevalencia de sistemas de gobiernos que ocluyen la participación paritaria de las mujeres en todos los ámbitos, a pesar de existir leyes de cuotas, aunque debemos insistir con ellas porque es la herramienta jurídica indispensable y legítima en los sistemas democráticos.

El liberalismo y el capitalismo en un mundo globalizado, quiere hacer retroceder a las mujeres en la conquista de sus derechos. La negación del derecho al aborto o sus restricciones suponen un modo de expropiación de los cuerpos de las mujeres, y las consecuencias que se derivan de ello, exhiben el crudo e implacable modo de disciplinamiento al que el sistema patriarcal no está dispuesto a renunciar, porque de ello depende su subsistencia. Las políticas de los gobiernos tendientes a la restricción en los servicios públicos de salud, los intentos de eliminación de causales de aborto, la criminalización de los profesionales, y la persecución a las defensoras de derechos humanos, son sólo algunos ejemplos de cómo se muestra esta ofensiva a escala global. La avanzada ultraconservadora contra los derechos sexuales y reproductivos de las mujeres ya está aquí, a la que se ha sumado la fuerza determinante de los grupos evangélicos -de gran presencia en nuestra región-, constituye un fenómeno de este siglo, que no podemos dejar de tener en cuenta.

Parecería que estamos ante varios frentes de batalla, sin embargo es uno que contiene múltiples variables; pero algo debe quedarnos en claro: las mujeres estamos discutiendo sobre el poder, porque de eso se trata cuando reclamamos libertad de decidir sobre nuestros cuerpos.

Por tanto, la resistencia y el combate a estas políticas que pretender conculcar nuestros derechos, debemos darlas desde el feminismo, que desde sus inicios ha sido un movimiento emancipatorio, y sigue siendo la senda a seguir, para ampliar los márgenes de nuestras democracias, construir ciudadanía y capacidad de agencia, para seguir luchando por la igualdad y la no discriminación de mujeres y niñas. 


\section{BIBLIOGRAFÍA}

Amorós Puente, C. (2014). Salomón no era Sabio. Madrid: Fundamentos.

Bohórquez Monsalve, V. (2015). De los derechos a los hechos: análisis del marco legal sobre el aborto en América Latina y el Caribe. En Investigación sobre aborto en América Latina y El Caribe: una agenda renovada para informar políticas públicas e incidencia (0), 153-172.

CRR - Center for Reproductive Rights. Alyne v. Brasil (2011) Disponible en https://www.reproductiverights.org/es/document/esp-Alyne-v-Brazil-Case-ofAlyne-da-Silva-Pimentel-Teixeira-v-Brazil

CRR - Center for Reproductive Rights (2014). Panorama mundial del derecho al aborto. Disponible en http:/ / www.worldabortionlaws.com/about.html

Cobo, R. y Nogueiras, B. (2014). Teoría y acción política feminista en España en torno al aborto. En León Alonso, M. y Sgro Ruata, M. (comp.) La reforma del aborto en España perspectivas de un debate (re)emergente (pp. 41-65). Argentina: Católicas por el derecho a decidir.

Deza, S. (2013). Violación de secreto médico y denuncia de aborto. Perspectivas bioéticas, 1 (34), 41-63.

Facio, A. (2014). La objeción de conciencia como herramienta de mayorías. En Deza, Soledad et. al.. (ed). Jaque a la reina: salud, autonomía y libertad reproductiva en Tucumán (pp. 213-277). Córdoba: Católicas por el Derecho a Decidir.

Facio, A. (2008). Los derechos reproductivos son derechos humanos. Instituto Interamericano de Derechos Humanos. 1. San José. Costa Rica.

Facio, A. (1992). Cuando el género suena cambios trae. Una metodología para el análisis de género del fenómeno legal. San José, Costa Rica: Ilanud.

Faundes, A. y Barzelatto, J. (2011). El drama del aborto En busca de un consenso. Buenos Aires. Paidós.

GIRE. Grupo de Información en Reproducción Elegida. (2017) Violencia sin Interrupción. Disponible en http:/ /aborto-por-violacion.gire.org.mx/assets/pdf/violencia_sin_interrupcio n.pdf

Instituto Guttmacher (2012). Hechos sobre el aborto en América Latina y el Caribe.

IPAS. 2016. Delatando a las mujeres: el deber de cada prestador/a de servicios de denunciar. Implicancias jurídicas y de derechos humanos para los servicios de salud reproductiva en Latinoamérica. Disponible en http://despenalizacion.org.ar/pdf/publicaciones/ipas2016.pdf 
IPAS Bolivia. (2018) Las cifras hablan II. Disponible en https://es.scribd.com/document/376182509/Las-Cifras-Hablan-II

OEA - Organización de los Estados Americanos (2012). Segundo Informe Hemisférico sobre la Implementación de la Convención de Belén do Pará. Mecanismo de Seguimiento de la Convención de Belén do Pará MESECVI. Disponible en https://www.oas.org/es/mesecvi/docs/mesecvi-segundoinformehemisfericoes.pdf

OEA - Organización de los Estados Americanos (2015). Comisión Interamericana de Derechos Humanos. Situación de derechos humanos en la República Dominicana. OEA/Ser.L/V/II. Doc. 42/15 31 diciembre 2015

OEA - Organización de los Estados Americanos (2017). Comisión Interamericana de Derechos Humanos Informe sobre pobreza y derechos humanos en las Américas. Disponible en http://www.oas.org/es/cidh/informes/pdfs/PobrezaDDHH2017.pdf

ONU - Organización de las Naciones Unidas (1984). Convención contra la Tortura y Otros Tratos o Penas Crueles, Inhumanos o Degradantes. Recuperado en http:// www.ohchr.org/SP/ProfessionalInterest/Pages/CAT.aspx

ONU - Organización de las Naciones Unidas (2004). Los derechos económicos, sociales y culturales. El derecho de toda persona al disfrute del más alto nivel posible de salud física y mental. Informe del Relator Especial, Sr. Paul Hunt.

ONU - Organización de las Naciones Unidas (2009) Informe del Comité contra la Tortura. $42^{\circ}$ período de sesiones. Recuperado en http://tbinternet.ohchr.org/_layouts/treatybodyexternal/Download.aspx? symbolno $=\mathrm{CAT} / \mathrm{C} / \mathrm{NIC} / \mathrm{CO} / 1 \&$ Lang $=\mathrm{En}$

ONU - Organización de las Naciones Unidas (2009) Comité para la Eliminación de la Discriminación contra la Mujer. L-C. vs. Perú. CEDAW/C/50/D/22/2009. Disponible en http://www.sipi.siteal.org/sites/default/files/sipi_file_file/p11_conv_eliminacion_di scriminacion_mujeres.pdf

ONU - Organización de las Naciones Unidas (2011) Comité de Derechos Humanos. CCPR/C/101/D/1608/2007. Disponible en http://juris.ohchr.org/Search/Details/1611

OMS - Organización Mundial de la Salud. (2012). Aborto sin riesgos: guía técnica y de politicas para sistemas de salud. Disponible en

http://www.who.int/reproductivehealth/publications/unsafe_abortion/9789241548434/ es/ 
CEPAL Observatorio de Igualdad y Género de América Latina y el Caribe (2017). Disponible en https://oig.cepal.org/es

Parlamento Europeo (2013). Informe sobre salud sexual y reproductiva y derechos afines (2013/2040(INI)) Comisión de Derechos de la Mujer e Igualdad de Género. Ponente: Edite Estrela. Disponible en http://www.europarl.europa.eu/meetdocs/2009_2014/documents/femm/dv/ p7 a(2013)0306/p7 a(2013)0306 es.pdf

Planned Parenthod (2010). Donde Roe no existe: Análisis del impacto del aborto ilegal en el mundo. En Reseña. Nueva York.

Puleo, Alicia H. (2010). Lo personal es político: el surgimiento del feminismo radical. En AMOROS, C. y DE MIGUEL, A. (eds.) Teoría feminista: de la Ilustración a la globalización. Del feminismo liberal a la posmodernidad (pp.35-67). Madrid: Minerva Ediciones.

Tames, R. (2012). ¿El derecho a la vida de quién? Disponible en http://repositorio.gire.org.mx/handle/123456789/885

Women'S Link Worldwide (2017) Guía para proteger los derechos sexuales y reproductivos de las mujeres ante el sistema interamericano. Disponible en http://www.womenslinkworldwide.org/files/3041/guia-para-proteger-los-derechossexuales-ante-el-sistema-interamericano.pdf 